\title{
Relationship between feeding modes and infant weight gain in the first month of life
}

\author{
SATOKO EBINA $^{1}$ and IKUO KASHIWAKURA ${ }^{2}$ \\ ${ }^{1}$ Sapporo Medical University, Graduate Course in Midwifery, Chuo-ku, Sapporo 060-8556; ${ }^{2}$ Department of \\ Radiological Life Sciences, Hirosaki University Graduate School of Health Sciences, Hirosaki 036-8564, Japan
}

Received July 13, 2012; Accepted September 25, 2012

DOI: $10.3892 /$ etm.2012.741

\begin{abstract}
Breast-feeding and human milk are beneficial for both mothers and their children. This retrospective study aimed to clarify whether differences in feeding mode influence infant weight gain in the first month of life. We analyzed the pregnancy charts of 422 women who delivered at a birthing center in rural Japan between August 1998 and September 2007. The inclusion criteria were low-risk, full-term pregnancy (duration, 37-42 weeks), spontaneous vaginal delivery, and a healthy infant (1 min Apgar score of $\geq 8$ ) who underwent a health check-up at 1 month postpartum. The subjects were classified into three groups on the basis of feeding modes: exclusive breast-feeding group (28.9\%), mixed-feeding group $(55.9 \%)$ and exclusive formula-feeding group (15.2\%). The weight gain/day was 39.7 $\pm 9.3 \mathrm{~g}$ (range, 18.5-67.4 g), 39.5 $\pm 9.4 \mathrm{~g}$ (range, 13.8-64.5 g) and 39.0 $\pm 9.5 \mathrm{~g}$ (range, 14.4-65.3 g) in the exclusive breast-feeding, mixed-feeding and exclusive formula-feeding groups, respectively. Apart from the rate of maternal smoking, which was lower in the exclusive breastfeeding group, no other significant differences were observed among the three groups. This study revealed that there were no differences in weight gain among infants raised exclusively on breast milk and those raised exclusively on formula milk.
\end{abstract}

\section{Introduction}

The American Academy of Pediatrics (1) and the World Health Organization (WHO) (2) recommend exclusive breast-feeding for infants until the age of 6 months. A US national survey conducted in 2001 reported that $33 \%$ of infants were breast-fed and $17 \%$ were exclusively breast-fed until 6 months of age (3). Breast-feeding is the ideal feeding mode for both infants and mothers. Breast-feeding has beneficial effects in infants and mothers, and it plays a crucial role in public health (1). Human

Correspondence to: Ms Satoko Ebina, Sapporo Medical University, Graduate Course in Midwifery, South 1 West 17, Chuo-ku, Sapporo 060-8556, Japan

E-mail: sebina@sapmed.ac.jp

Key words: breast-feeding, feeding mode, infant weight gain milk is species-specific and contains optimal nutrients, growth factors and the immunological components required for infants (4). Breast-feeding has short-term benefits such as the prevention of infectious diseases in infants, including diarrhea (5-8), respiratory tract infection $(9-12)$ and otitis media $(13,14)$. The long-term health benefits of breast-feeding in infants include a lower risk of developing diseases such as obesity $(15,16)$, hypertension $(17,18)$ and type 1 diabetes mellitus $(19,20)$ in adulthood. Gluckman and Hanson (21) proposed the concept of developmental origins of health and disease, which states that unbalanced nutrition in utero and in infancy leads to subsequent disorders.

Body weight is an important index of infant growth and development. Neonates lose weight because of the physiologic extracellular fluid diuresis following their transition from intrauterine to extrauterine life (22). The normal maximal weight loss is $5.5-6.6 \%$ of birth weight in optimally exclusively breast-fed infants and occurs between the second and third day of life $(23,24)$. According to the WHO Multicentre Growth Reference Study, a male infant gains 1,200 g/month and a female infant gains $1,000 \mathrm{~g} / \mathrm{month}$ under optimal conditions. Weight gain in the first month of life in exclusively breast-fed infants is reported to be $18-35 \mathrm{~g}(25,26)$. Although studies indicate sufficient evidence regarding breast-feeding, there is no universal agreement among healthcare providers regarding weight gain in breast-fed and formula-fed infants. When weight gain occurs gradually, appropriate support should be provided after determining whether the infant is demonstrating delayed weight gain or a failure to thrive (27-29).

This retrospective study aimed to clarify whether differences in feeding modes influence neonatal weight gain in the first month of life.

\section{Materials and methods}

Study population. This retrospective study involved the review of pregnancy charts of 422 women who delivered at a birthing center in Aomori Prefecture, Japan. The study complied with the principles of the Declaration of Helsinki (Seoul 2008) and the ethical guidelines for epidemiological research issued by the Ministry of Education, Culture, Sports, Science and Technology as well as the Ministry of Health, Labour and Welfare in Japan (2008). All study data were obtained from the medical records of the subjects and were coded to avoid 
Table I. Summary and comparison of maternal parameters classified on the basis of feeding modes.

\begin{tabular}{|c|c|c|c|c|}
\hline \multirow[b]{2}{*}{ Parameters } & \multirow[b]{2}{*}{$\begin{array}{l}\text { Total population } \\
\qquad(\mathrm{n}=422)\end{array}$} & \multicolumn{3}{|c|}{ Feeding mode group } \\
\hline & & $\begin{array}{l}\text { Breast-fed } \\
(n=122)\end{array}$ & $\begin{array}{l}\text { Mixed-fed } \\
(n=236)\end{array}$ & $\begin{array}{l}\text { Formula-fed } \\
\qquad(n=64)\end{array}$ \\
\hline Age $(\text { years })^{\mathrm{a}}$ & $26.6 \pm 4.5$ & $26.8 \pm 4.0$ & $26.6 \pm 4.7$ & $26.3 \pm 4.9$ \\
\hline Duration of pregnancy (weeks) ${ }^{\mathrm{a}}$ & $39.5 \pm 1.2$ & $39.5 \pm 1.1$ & $39.6 \pm 1.2$ & $39.2 \pm 1.1^{\mathrm{b}}$ \\
\hline Primiparous $^{c}$ & $163(38.6)$ & $44(36.1)$ & $96(40.7)$ & $23(35.9)$ \\
\hline Smokers $^{c}$ & $75(17.8)$ & $9(7.4)$ & $48(20.3)$ & $18(28.1)^{\mathrm{d}}$ \\
\hline Prepregnancy weight $(\mathrm{kg})^{\mathrm{a}}$ & $53.3 \pm 8.4$ & $52.4 \pm 6.8$ & $53.7 \pm 9.3$ & $54.0 \pm 7.5$ \\
\hline Prepregnancy BMI ${ }^{\mathrm{a}}$ & $21.2 \pm 3.2$ & $20.8 \pm 2.4$ & $21.4 \pm 3.5$ & $21.4 \pm 3.1$ \\
\hline Delivery weight & $65.2 \pm 8.7$ & $64.2 \pm 7.4$ & $65.7 \pm 9.2$ & $65.3 \pm 8.9$ \\
\hline Gestational weight gain $(\mathrm{kg})^{\mathrm{a}}$ & $11.8 \pm 4.0$ & $11.7 \pm 3.4$ & $12.0 \pm 4.3$ & $11.3 \pm 3.9$ \\
\hline Weight at 1 month postpartum $(\mathrm{kg})^{\mathrm{a}}$ & $57.9 \pm 8.3$ & $57.0 \pm 7.2$ & $58.4 \pm 8.9$ & $57.6 \pm 8.1$ \\
\hline Postpartum weight loss $(\mathrm{kg})^{\mathrm{a}}$ & $7.3 \pm 2.3$ & $7.2 \pm 2.1$ & $7.3 \pm 2.3$ & $7.7 \pm 2.6$ \\
\hline
\end{tabular}

Values are presented as means $\pm \mathrm{SD}$. BMI, body mass index [weight in kilograms divided by the square of the height in meters $\left(\mathrm{kg} / \mathrm{m}^{2}\right)$ ]; ${ }^{\mathrm{a}}$ One-way analysis of variance, ${ }^{\mathrm{b}} \mathrm{P}<0.05$. ${ }^{\mathrm{C}}$ Presented as number and percent and analyzed with the $\chi^{2},{ }^{\mathrm{d}} \mathrm{P}<0.01$.

disclosure of the their identity. We gathered the medical records of 579 women who had a singleton pregnancy and delivered a live infant from August 1998 to September 2007. The inclusion criteria were low-risk, full-term pregnancy (duration, 37-42 weeks), spontaneous vaginal delivery, <500 ml intrapartum blood loss and a healthy infant (1 min Apgar score of $\geq 8$ ) who underwent a health check-up at 1 month postpartum. Mothers with chronic diseases (e.g., diabetes, hypertension and hyperthyroidism), gestational diabetes, and pregnancyinduced hypertension were excluded from the study. Records with unknown or missing obstetric data were not included. A total of 422 records were finally available for analysis.

Perinatal parameters. The perinatal parameters extracted from the pregnancy charts were maternal age, parity, smoking status, self-reported prepregnancy weight, prepregnancy body mass index (BMI), gestational weight gain, chronic diseases, delivery mode, duration of pregnancy, infant gender, infant size at birth (weight, height, head circumference and chest circumference), 1 min Apgar score, admission to hospital, and data from the first month health check-up (mother's weight, feeding mode and infant size).

Feeding modes. Subjects were divided into three groups on the basis of self-reported feeding mode used by mothers in the first postpartum month: an exclusive breast-feeding group, a mixed-feeding (breast-feeding and formula-feeding) group, and an exclusive formula-feeding group.

Statistical analysis. Statistical analysis was performed using SPSS software, version 16.0 (SPSS Japan, Inc., Tokyo, Japan) for Windows. Descriptive statistics are indicated as arithmetic mean \pm standard deviation. A two-sample t-test, one-way analysis of variance, and Tukey's honestly significant difference test were performed to determine differences across the three groups. The $\chi^{2}$ statistic was used to analyze categorical variables. Univariate analysis was performed using Pearson's correlation coefficient. A P-value of $<0.05$ was determined to be indicative of a statistically significant result.

\section{Results}

Summary of the study population. The maternal parameters of the study population are summarized in Table I. The mean maternal age was $26.6 \pm 4.5$ years (range, $17-38$ years); $38.6 \%$ subjects were primiparas and $17.8 \%$ were smokers. The mean duration of pregnancy was $39.5 \pm 1.2$ weeks. The infant parameters of the study population are summarized in Table II. The mean infant birth weight and height were 3,209 $\pm 370.4 \mathrm{~g}$ and $49.6 \pm 1.8 \mathrm{~cm}$, respectively; $49.8 \%$ infants were male. The mean infant weight and height at 1 month were 4,513.2 $\pm 451 \mathrm{~g}$ and $54.9 \pm 1.6 \mathrm{~cm}$, respectively; the mean total weight gain was $1,303.5 \pm 325.0 \mathrm{~kg}$, and the weight gain/day was $39.5 \pm 9.4 \mathrm{~g}$. The study population was classified into the following three groups on the basis of the feeding mode: breast-feeding $(28.9 \%)$, mixed-feeding $(55.9 \%)$ and formula-feeding $(15.2 \%)$ groups. The overall maternal smoking rate was $17.8 \%$, the smoking rates for the exclusive breast-feeding, mixed feeding, and exclusive formula-feeding groups were 7.4, 20.3 and $28.1 \%$, respectively. The smoking rate was significantly lower in the exclusive breast-feeding group than in the other groups. Except for maternal smoking status, none of the other maternal and infant parameters significantly differed among the three feeding modes.

Relationship between weight gain and maternal/neonatal parameters. Infant weight gain/day in the first month of life was determined for feeding modes, parity and infant gender (Fig. 1). The daily weight gain was 39.7 $\pm 9.3 \mathrm{~g}$ (range, 18.5$67.4 \mathrm{~g}$ ) in the exclusive breast-feeding group, $39.5 \pm 9.4 \mathrm{~g}$ (range, 13.8-64.5 g) in the mixed-feeding group, and $39.0 \pm 9.5 \mathrm{~g}$ (range, 14.4-65.3 g) in the exclusive formula-feeding group. 
Table II. Summary and comparison of infant parameters classified on the basis of feeding modes.

\begin{tabular}{|c|c|c|c|c|}
\hline \multirow[b]{2}{*}{ Parameters } & \multirow[b]{2}{*}{$\begin{array}{l}\text { Total population } \\
\qquad(\mathrm{n}=422)\end{array}$} & \multicolumn{3}{|c|}{ Feeding modes group } \\
\hline & & $\begin{array}{l}\text { Breast-fed } \\
(\mathrm{n}=122)\end{array}$ & $\begin{array}{l}\text { Mixed-fed } \\
(\mathrm{n}=236)\end{array}$ & $\begin{array}{l}\text { Formula-fed } \\
\quad(\mathrm{n}=64)\end{array}$ \\
\hline Male $^{\mathrm{a}}$ & $210(49.8)$ & $52(42.6)$ & $126(53.4)$ & $32(50.0)$ \\
\hline 1 min Apgar score ${ }^{b}$ & $9.8 \pm 0.4$ & $9.8 \pm 0.4$ & $9.8 \pm 0.4$ & $9.7 \pm 0.5$ \\
\hline \multicolumn{5}{|l|}{ Birth } \\
\hline Weight $(g)^{b}$ & $3,209.0 \pm 370.4$ & $3,203.6 \pm 319.6$ & $3,222.3 \pm 402.5$ & $3,170.6 \pm 337.6$ \\
\hline Height $(\mathrm{cm})^{\mathrm{b}}$ & $49.6 \pm 1.8$ & $49.6 \pm 1.6$ & $49.7 \pm 2.0$ & $49.5 \pm 1.7$ \\
\hline Head circumference $(\mathrm{cm})^{\mathrm{b}}$ & $33.4 \pm 1.3$ & $33.3 \pm 1.3$ & $33.5 \pm 1.3$ & $33.3 \pm 1.2$ \\
\hline Chest circumference $(\mathrm{cm})^{\mathrm{b}}$ & $31.7 \pm 1.6$ & $31.6 \pm 1.5$ & $31.8 \pm 1.6$ & $31.3 \pm 1.7$ \\
\hline \multicolumn{5}{|l|}{ At 1 month of life } \\
\hline Weight $(g)^{b}$ & $4,513.2 \pm 451.8$ & $4,504.2 \pm 447.8$ & $4,525.3 \pm 470.3$ & $4,485.5 \pm 390.4$ \\
\hline Height $(\mathrm{cm})^{\mathrm{b}}$ & $54.9 \pm 1.6$ & $54.8 \pm 1.5$ & $55.0 \pm 1.8$ & $54.8 \pm 1.3$ \\
\hline Head circumference $(\mathrm{cm})^{\mathrm{b}}$ & $37.1 \pm 1.1$ & $37.2 \pm 1.0$ & $37.2 \pm 1.1$ & $37.4 \pm 1.4$ \\
\hline Chest circumference $(\mathrm{cm})^{\mathrm{b}}$ & $37.1 \pm 1.4$ & $37.1 \pm 1.3$ & $37.0 \pm 1.4$ & $37.1 \pm 1.2$ \\
\hline
\end{tabular}

Values are presented as mean \pm SD. ${ }^{a}$ Presented as number and percent and analyzed with the $\chi^{2}$, NS. ${ }^{b}$ One-way analysis of variance, NS; NS, not significant.

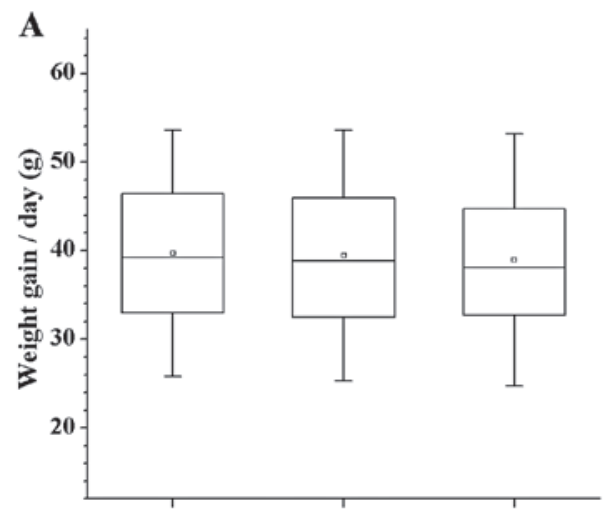

Breast-feeding Mixed-feeding Formula-feeding

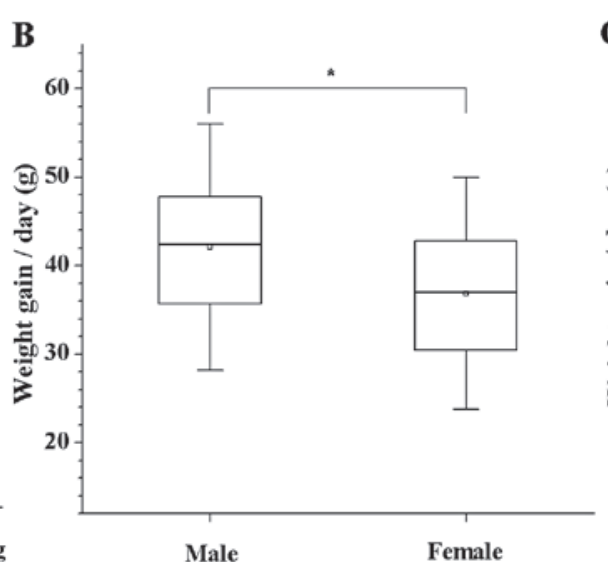

Figure 1. Infant weight gain/day in the first month of life classified on the basis of feeding mode, infant gender, and parity. No significant differences were observed in weight gain/day among (A) the three feeding modes or (C) parity. (B) However, weight gain/day was higher in male infants than in female infants (42.1 \pm 9.3 g vs. $\left.36.9 \pm 8.8 \mathrm{~g} ;{ }^{*} \mathrm{P}<0.05\right)$.

Table III. Multiple linear regression analysis for the association between infant weight gain/day and maternal/infant parameters.

\begin{tabular}{lc}
\hline Explanatory variable & $\begin{array}{c}\text { Standardized partial } \\
\text { regression coefficient }(\beta)\end{array}$ \\
\hline Infant gender & $-0.276^{\mathrm{a}}$ \\
Birth weight & $-0.378^{\mathrm{a}}$ \\
Birth height & $0.255^{\mathrm{b}}$ \\
Maternal age & $-0.119^{\mathrm{c}}$ \\
\hline
\end{tabular}

Coefficient of determination, $\mathrm{R}^{2}=0.13$. ${ }^{\mathrm{a} P}<0.001,{ }^{\mathrm{b}} \mathrm{P}<0.01,{ }^{\mathrm{C}} \mathrm{P}<0.05$.
No significant differences in daily weight gain were observed among the feeding modes (Fig. 1A). The daily infant weight gain was significantly higher in the male infants $(42.1 \pm 9.3 \mathrm{~g})$ than in the female infants $(36.9 \pm 8.8 \mathrm{~g}$ ) (Fig. 1B), but did not differ between primiparous and multiparous mothers (Fig. 1C).

Multiple linear regression analysis was used to identify independent variables associated with infant weight gain (Table III). Although the coefficient of determination $\left(\mathrm{R}^{2}\right)$ was low, infant gender, birth weight, birth height, and maternal age were identified as variables that could independently predict the weight gain/day in the first month of life $\left(\mathrm{R}^{2}=0.13, \mathrm{P}<0.001\right.$ by ANOVA). 


\section{Discussion}

In Japan, breast-feeding has been promoted since 1989 according to a joint announcement 'The Ten Steps to Successful Breastfeeding' released by WHO/UNICEF. According to a national Japanese study in $2005,42.4 \%$ infants aged 1 month, $38.0 \%$ aged 3 months, and $34.7 \%$ aged 6 months were exclusively breast-fed (30). However, in our retrospective study, $28.9 \%$ infants were exclusively breast-fed at 1 month after birth, indicating that the values in our study in Japan were below the national average. The results obtained in the present study were possibly affected by regional characteristics, different attitudes, and/or lack of education on breast-feeding. Moreover, relatively higher birth weights of both male $(3,235 \mathrm{~g})$ and female $(3,183 \mathrm{~g})$ infants were observed in our study when compared with the average birth weight in Japan (male infants, 3,040 g; female infants, 2,960 g) (31). This finding may be attributed to the low-risk pregnancies, young maternal age, and high rate of multiparity and full-term deliveries in our study. Except for the rate of maternal smoking, which was lower in the exclusive breast-feeding group than in other groups, none of the other maternal and infant parameters assessed in this study significantly differed among the three groups.

According to the WHO Multicenter Growth Reference Study, a male infant gains 1,200 g/month and a female infant gains $1,000 \mathrm{~g} /$ month under optimal conditions (25). In the current study, the male infants gained 1,391.1 $\pm 328.4 \mathrm{~g} / \mathrm{month}$ (42 g/day) and the female infants gained 1,216.7 $\pm 297.7 \mathrm{~g} / \mathrm{month}$ (36.9 g/day). WHO (32) and Dewey (33) reported that male infants gain significantly more weight than female infants. Breast-fed infants weighed significantly less than formula-fed infants at ages 3 months to 2 years; however, no significant differences in weight were observed at age 2-3 months (34-36). The weight gained in the first month after birth did not differ with the feeding modes; this finding was consistent with that of a previous study (24). Exclusively breast-fed infants may gradually gain weight in the first month of life. However, delayed weight gain cannot be disregarded as it may be associated with less than optimal breast-feeding or illness in the infant (e.g., congenital heart disease, neuromuscular disease, infection, or endocrine and metabolic abnormalities). Therefore, infant weight gain assessments must take into account potential illnesses in addition to maternal health, the condition of breast milk, and infant position and latching during breast-feeding. Furthermore, some infants gain less than $20 \mathrm{~g}$ /day regardless of the feeding mode. Factors affecting the mother's and infant's health after childbirth include abuse, parenting anxiety, and postpartum depression; therefore, the mother's physical and mental state should be assessed along with the infant's condition. Continuous support provided to the mother and infant soon after discharge from the hospital is related with improved health of both the mother and her infant.

The present study revealed that weight gain in the first month of life does not significantly differ between exclusively breast-fed infants and exclusively formula-fed infants (Fig. 1). Poor weight gain in infants is not only caused by poor milk intake due to incorrect suckling or insufficient lactation but may also be associated with illness in the infant. Breastfeeding improves the health and development of both the mother and infant. Therefore, assessment of feeding soon after birth is crucial with regard to infant growth and development and prevention of diseases in adulthood. Healthcare providers working with mothers and infants should understand the patterns of growth and development of exclusively breast-fed infants, correctly assess the effectiveness of breast-feeding, and provide continuous support so that both the mother and infant benefit from breast-feeding.

\section{Acknowledgements}

We are indebted to the midwives of Fukushi Birth Center for collecting the pregnancy charts. This study was supported by a Grant for Hirosaki University Institutional Research (2011).

\section{References}

1. American Academy of Pediatrics: Breastfeeding and the use of human milk. Pediatrics 115: 196-506, 2005.

2. WHO: Global Strategy for Infant and Young Child Feeding. 55th World Health Assembly. World Health Organization, Geneva, 2002.

3. Ryan AS, Wenjun Z and Acosta A: Breastfeeding continues to increase into the new millennium. Pediatrics 110: 1103-1109, 2002.

4. Prentice A: Constituents of human milk. In: Food and Nutrition Bulletin. United Nations University Press 17, 1996. http:// archive.unu.edu/unupress/food/8F174e/8F174E04.htm. Accessed December 27, 2011.

5. Howie PW, Forsyth JS, Ogston SA, Clark A and Florey CD: Protective effect of breast feeding against infection. BMJ 300: $11-16,1990$

6. Clemens J, Rao M, Ahmed F, et al: Breast-feeding and the risk of life-threatening rotavirus diarrhea: prevention or postponement? Pediatrics 92: 680-685, 1993

7. Lopez-Alarcon M, Villalpando S and Fajardo A: Breast-feeding lowers the frequency and duration of acute respiratory infection and diarrhea in infants under six months of age. J Nutr 127: 436-443, 1997.

8. Bhandari N, Bahl R, Mazumdar S, Martines J, Black RE and Bhan MK; Infant Feeding Study Group: Effect of communitybased promotion of exclusive breastfeeding on diarrhoeal illness and growth: a cluster randomized controlled trial. Lancet 361: 1418-1423, 2003.

9. Blaymore Bier J, Oliver T, Ferguson A and Vohr BR: Human milk reduces outpatient upper respiratory symptoms in premature infants during their first year of life. J Perinatol 22: 354-359, 2002.

10. Bachrach VR, Schwarz E and Bachrach LR: Breastfeeding and the risk of hospitalization for respiratory disease in infancy: a meta-analysis. Arch Pediatr Adolesc Med 157: 237-243, 2003.

11. Chantry CJ, Howard CR and Auinger P: Full breastfeeding duration and associated decrease in respiratory tract infection in US children. Pediatrics 117: 425-432, 2006.

12. Wright AL, Holberg CJ, Martinez FD, Morgan WJ and Taussig LM: Breast feeding and lower respiratory tract illness in the first year of life. Group Health Medical Associates. BMJ 299: 946-949, 1989.

13. Owen MJ, Baldwin CD, Swank PR, Pannu AK, Johnson DL and Howie VM: Relation of infant feeding practices, cigarette smoke exposure, and group child care to the onset and duration of otitis media with effusion in the first two years of life. J Pediatr 123: 702-711, 1993.

14. Aniansson G, Alm B, Andersson B, et al: A prospective cohort study on breast-feeding and otitis media in Swedish infants. Pediatr Infect Dis J 13: 183-188, 1994.

15. Von Kries R, Koletzko B, Sauerwald T, et al: Breast feeding and obesity: cross sectional study. BMJ 319: 147-150, 1999.

16. Owen CG, Martin RM, Whincup PH, Smith GD and Cook DG: Effect of infant feeding on the risk of obesity across the life course: a quantitative review of published evidence. Pediatrics 115: 1367-1377, 2005.

17. Singhal A, Cole TJ and Lucas A: Early nutrition in preterm infants and later blood pressure: two cohorts after randomised trials. Lancet 357: 413-419, 2001. 
18. Horta BL, Bahl R, Martinés JC and Victora CG: Evidence on the long-term effects of breastfeeding: Systematic reviews and meta-analysis. World Health Organization, Geneve, pp52, 2007.

19. Virtanen SM, Räsänen L, Aro A, et al: Infant feeding in Finnish children less than $7 \mathrm{yr}$ of age with newly diagnosed IDDM. Childhood Diabetes in Finland Study Group. Diabetes Care 14: 415-417, 1991.

20. Gerstein HC: Cow's milk exposure and type I diabetes mellitus. A critical overview of the clinical literature. Diabetes Care 17: 13-19, 1994.

21. Gluckman $P$ and Hanson $M$ (eds): The conceptual basis for the developmental origins of health and disease. In: Developmental Origins of Health and Disease. Cambridge University Press, Camdridge, pp33-50, 2006.

22. Cunningham FG, Leveno KJ, Bloom SL, et al: The newborn infant. In: Williams Obstetrics. Cunningham FG, Leveno KJ and Bloom S (eds). 23rd edition, McGraw-Hill, New York, pp590-604, 2010.

23. Rodríguez G, Ventura P, Samper MP, Moreno L, Sarría A and Pérez-González JM: Changes in body composition during the initial hours of life in breast-fed healthy term newborns. Biol Neonate 77: 12-16, 2000.

24. MacDonald PD, Ross SR, Grant L and Young D: Neonatal weight loss in breast and formula fed infants. Arch Dis Child Fetal Neonatal Ed 88: F472-F476, 2003.

25. WHO: Evidence for the ten steps to successful breastfeeding. World Health Organization, Geneva, 1999.

26. UNICEF-World Health Organization: Breastfeeding Management and Promotion in a Baby-Friendly Hospital: an 18-hour course for maternity staff. UNICEF, New York, 1993.
27. Mohrbancher N and Stock JMA (eds): The Breastfeeding Answer Book. La Leche League International, Illinois, pp147-178, 2003.

28. Lawrence RA and Lawrence RM: Breastfeeding; A Guide for the Medical Profession. Mosby, St. Louis, pp427-460, 2005.

29. Regina E and Giugliani J: Slow weight gain and failure to thrive. In: Core Curriculum for Lactation Consultant Practice. 2nd edition. Mannel R, Martens P and Walker M (eds.). Jones and Bartlett Publishers, Boston, pp727-740, 2007.

30. Ministry of Health, Labour and Welfare (http://www.mhlw. go.jp/) Japan: Summary of the results of a nutrition survey in infants in FY2005, Breast-feeding division (updated 2006 Jun 29). Available at http://www.mhlw.go.jp/shingi/2007/03/dl/ s0314-17b-1.pdf (In Japanese). Accessed December 27, 2011.

31. Health, Labour and Welfare Statistics Association. Journal of Health and Welfare Statistics 58: 48, 2011 (In Japanese).

32. World Health Organization: The WHO Multicentre Growth Reference Study. http://www.who.int/childgrowth/mgrs/en/. Accessed December 27, 2011.

33. Dewey KG: Nutrition, growth, and complementary feeding of the breastfed infant. Pediatr Clin North Am 48: 87-104, 2001

34. Dewey KG, Heinig MJ, Nommsen LA, Peerson JM and Lönnerdal B: Growth of breast-fed and formula-fed infants from 0 to 18 months: the DARLING Study. Pediatrics 89: 1035-1041, 1992.

35. Kramer MS, Guo T, Platt RW, Vanilovich I, et al: The promotion of breastfeeding intervention trials study group. Feeding effects on growth during infancy. J Pediatr 145: 600-605, 2004.

36. Dewey KG: Infant feeding and growth. Adv Exp Med Biol 639: 57-66, 2009. 